\section{A Beginners Guide to the Metabolism, Functions and Pharmacological Potential of Sphingolipids}

\section{Nicholas JD Wright*}

Wingate University School of Pharmacy, Wingate University, Wingate, North Carolina, USA

\begin{abstract}
This brief review is designed to acquaint the reader with a basic understanding of the functions of sphingolipids in the newly emerging field of lipidomics. This includes the derived so-called complex sphingolipids found in membranes. Sphingolipids have been implicated as important messenger molecules in many areas of cell function including cell growth, apoptosis, inflammation and migration. Complex sphingolipids have been shown to be involved in vital membrane functions such as receptor clustering and vesicle trafficking. Obviously these functions are significant factors in the progression of many disease states such as the development of cancerous cells and tumorigenesis. Accordingly these lipid messengers and membrane components have attracted much pharmaceutical interest and useful drugs are now starting to be approved and prescribed for patients in the U.S. This review introduces sphingolipid metabolism and function and briefly discusses their exploitation for drug development.
\end{abstract}

Keywords: Apoptosis; Cancer; Drug targets; Sphingolipids

\section{Introduction}

Sphingolipids are a very important and large family of interrelated lipid molecules at the forefront of the newly emerging field of lipidomics [1]. Since the discovery that Diacylglycerol (DAG), a lipid derived from membrane components via the action of phospholipase $\mathrm{C}$, acts as a so-called secondary messenger to activate protein kinase $\mathrm{C}$ and the liberation of arachidonic acid by phospholipase $\mathrm{A}_{2}$ as a precursor for eicosanoid production $[2,3]$, the idea that lipids were just for energy storage or passive membrane components was redundant. It is now widely accepted that many lipids, especially sphingolipids, are vital in signaling and regulating very important cellular processes including cell growth, apoptosis, inflammation and migration [1]. However,

*Corresponding author: Nicholas JD Wright, Wingate University School of Pharmacy, Wingate University, Wingate, North Carolina 28174, USA, Tel: 704233-8392; E-mail: n.wright@wingate.edu

Citation: Nicholas JD Wright (2016) A Beginners Guide to the Metabolism, Functions and Pharmacological Potential of Sphingolipids. J Pharmacol Pharmaceut Pharmacovigil 1: 001.

Received: September 22, 2016; Accepted: December 01, 2016; Published: January 2, 2017

Copyright: @ 2016 Wright NJD, This is an open-access article distributed unde the terms of the Creative Commons Attribution License, which permits unrestricted use, distribution, and reproduction in any medium, provided the original author and source are credited. unlike the relatively simple and linear signaling pathway of the ubiquitous secondary messenger cyclic adenosine mono phosphate, there are significant additional layers of complexity that must be considered with sphingolipids. For simplicity in this review the term sphingolipid is used for all of the molecules illustrated in figure 1 (excluding the de novo starting molecules utilized by the transferase and the degradation products produced by the lyase) regardless of whether they have been found to have signaling functions. As mentioned these are a large family of interrelated signaling molecules (Figure 1), some of which can exhibit opposite effects on the same cellular process such as apoptosis. Being interrelated means disruption of one part of the pathway can produce a "ripple effect," affecting the levels of several of these molecules in turn [1]. Physically, some sphingolipids are very hydrophobic so limiting them to a particular organelle membrane, often where synthesized, or even a specific membrane face. Other sphingolipids are more hydrophilic and can enter the cytoplasm. There can also be differences in the alkyl chain lengths, position and number of double bonds and additional chemical groups (typically hydroxyl). There are currently 6 known isoforms of the enzyme Ceramide Synthase (CerS; also known as sphingosine $\mathrm{N}$-acyltransferase) which is central in sphingolipid metabolism (Figure 1) and these iso forms exhibit preferences for acyl CoA's of different chain lengths (16 vs.18 vs.24 carbons) $[4,5]$. Sphingolipids are also converted into so-called "complex" sphingolipids by the addition of various "head groups" (such as phosphocholine, glucose or galactose) to become more amphipathic membrane components. In addition ceramide is used in the important group of membrane components known as gangliosides which are sialylated glycol sphingolipids found in cell membranes generally but in particular in the grey matter of the CNS [6,7]. Complex sphingolipids have been implicated in such important functions as endocytosis and receptor clustering and the formation of functional microdomains or so-called "lipid rafts" in cell membranes. Additionally gangliosides are involved in brain development and thought to be involved in synaptic transmission and the modifications implicated in such vital processes as learning and memory [8]. The sphingolipid ceramide itself can be a membrane component and is found in higher than normal levels in these microdomains involved in certain signaling pathways both in plasma and mitochondrial membranes [9]. Complex sphingolipids are themselves recycled and can add to and affect the pool of simpler sphingolipids (Figure 1). Virtually all the published data on sphingolipid function was obtained from research utilizing laboratory animals or cultured cells. A brain sphingolipid ("sphingosin") was actually first described in the $19^{\text {th }}$ century [10] but it was not until 1947 that the collective term sphingolipid was applied [11] and by 1983 many individual sphingolipids had been described [12]. Sphingolipids are defined by a sphingoid base backbone (1,3-dihydroxy, 2-aminoalkane) typified by sphingosine (Figure 2). Sphingosine is specifically D-erythro-1,3-dihydroxy, 2-aminooctadec-4-ene (also known as trans-4-sphingenine). Sphingolipids can vary in chain length, position and number of double bonds and other functional groups such as a hydroxyl group at position 4 . Most mammalian sphingolipids studied so far contain an 18 carbon alkyl chain and therefore the following discussion focuses on these variants but the obvious potential for a vast super family of these molecules varying in 
chain length, etc. should not be overlooked. For an extremely detailed and comprehensive review of the structure of sphingolipids the reader is recommended to access the Merrill laboratory web site [13; www.sphingomap.org].

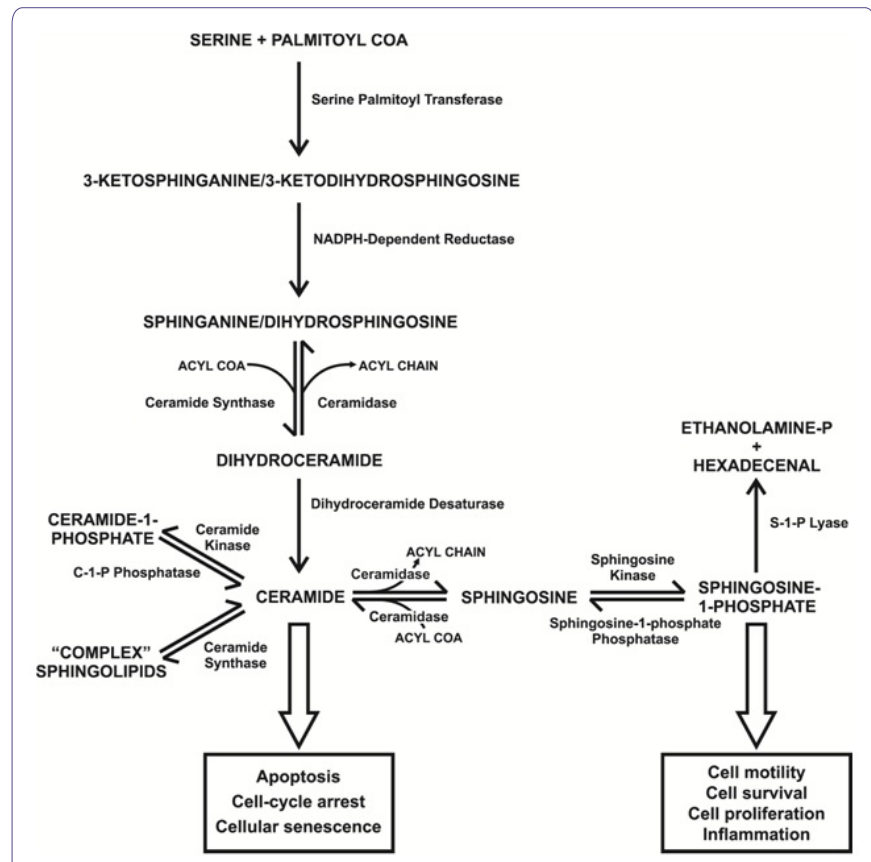

Figure 1: Summary of the metabolic pathways of the most important sphingolipids showing their interrelationships. De novo sphingolipid synthesis starts with serine and palmitoyl CoA while the recycling of "complex" sphingolipids will also affect the levels of these compounds. The two most currently researched intermediates, ceramide and Sphingosine-1-Phosphate (S-1-P), are highlighted with their principal and often antagonistic actions; the so-called sphingolipid "rheostat" can be visualized as the metabolic linking of "complex" sphingolipids (far left) to S-1-P (far right) via ceramide and sphingosine. Single arrows denote an irreversible step while dual arrows indicate a reversible step; $\mathrm{C}-1-\mathrm{P}$ is ceramide-1-phosphate.

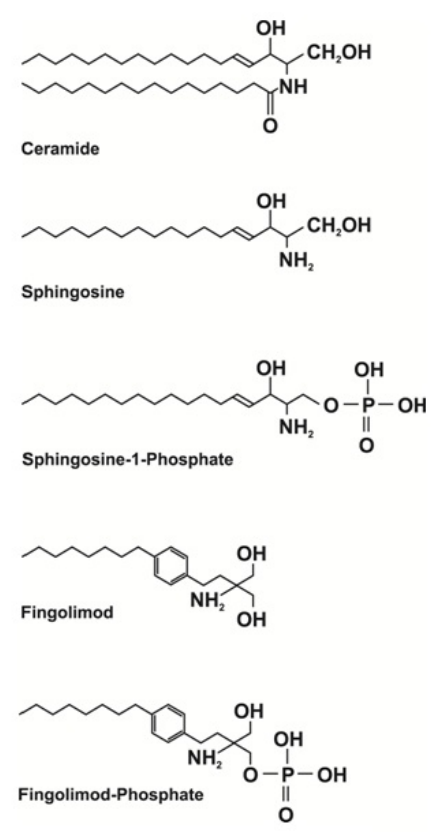

Figure 2: Cartoons comparing the structures of the most important sphingolipids plus the drug fingolimod and its active phosphorylated metabolite fingolimod phosphate.

\section{Sphingolipid Metabolism}

A detailed review of sphingolipid metabolism is beyond the scope of this review but is covered in-depth in the book "Sphingolipids as Signaling and Regulatory Molecules" [14]. To summarize, de novo sphingolipid synthesis starts with the condensation of the amino acid serine with palmitoyl-CoA to form 3-keto-dihydrosphingosine (also known as 3-ketosphinganine) catalyzed by serine palmitoyl transferase in the endoplasmic reticulum [15] (Figure 1). It has been shown in yeast and mouse fibroblast LM cells that a serine influx can drive de novo synthesis [16,17]. An abnormal subunit in this enzyme is responsible for hereditary sensory Neuropathy Type 1 which was the first human genetic disease associated with sphingolipid metabolism $[18,19]$. The 3-keto-dihydrosphingosine is then reduced to form dihydrosphingosin (also known as sphinganine) by an NADPH-dependent reductase [20]. This is followed by addition of an acyl chain of variable length by amide formation via the action of CerS [4,21]. This reaction can be reversed by one of several ceramidases which exhibit organelle-specific expression and, like the sphingomyelinases, various $\mathrm{pH}$ optimums (acid, neutral and alkaline) [22,23]. The resulting molecule is known as dihydroceramide and is normally modified by the addition of a double bond in the 4-5 position by dihydroceramide desaturase [24] to form ceramide (Figure 2). Ceramide can be considered a common central point or "hub" in sphingolipid metabolism [1] (Figure 1). It was thought initially that dihydroceramide might have specific biological activity but research, especially concerning the activation of protein phosphatase $2 \mathrm{~A}$ ( $\mathrm{PP} 2 \mathrm{~A})$, has shown that ceramide itself has far more activity for all targets discovered so far [25]. Ceramide can then be phosphorylated via ceramide kinase after transportation to the golgi apparatus [26] to form ceramide-1-phosphate and this reaction can also be reversed by ceramide-1-phosphate phosphatase [27]. Ceramide in particular has important messenger functions that will be discussed later. Ceramide is also the main entry point to complex sphingolipid generation which occurs principally in the golgi apparatus. However, ceramide is very hydrophobic and needs to be transported to the golgi apparatus either via vesicular transport or by binding to the Ceramide Transfer Protein [28] (CERT: figure 3 ). Once in the Golgi various head groups such as glucose, galactose or phosphocholine can be added to the $\mathrm{C} 1$ position via the action of glucosylceramide synthase, ceramide galactosyltransferase or sphingomyelin synthase respectively $[29,30]$. These complex sphingolipids can be recycled via various hydrolases to release ceramide back into the sphingolipid pool $[31,32]$. Sphingomyelin is broken down first to ceramide via the action of one of several sphingomyelinases, each with a different optimum $\mathrm{pH}$ and location on the plasma membrane (outer vs. inner faces) [33] and then to sphingosine via ceramidase. Although both ceramide and sphingosine can "flip flop" across the plasma membrane (neutral lipids unlike the phosphate derivatives which cannot "flip flop:" figure 3) their hydrophobicity means they can only be recycled back into the cell by endocytosis. After internalization and fusing with lysosomes, sphingomyelinases and ceramidases again participate in the breakdown and recycling of complex sphingolipids $[1,34]$. One can therefore see that there are 2 entry points into these interconnected pathways: de novo synthesis and the recycling of complex sphingolipids (Figure 1). Ceramide can be converted directly to sphingosine by several ceramidases and in the reverse direction by CerS (sphingosine to ceramide) similarly to the dihydroderivatives. Sphingosine itself can also be phosphorylated, via either of 2 Sphingosine Kinases [35] (SphK1 and 2: reversed by sphingosine phosphate phosphatase) [36] to produce Sphingosine-1-Phosphate 
(S-1-P: Figure 2). Sphingosine-1-phosphate, like ceramide, is an important messenger molecule whose functions will be discussed later [37]. It is also the so-called "exit point" from sphingolipid metabolism as the action of sphingosine-1-phosphate lyase irreversibly breaks it down into ethanolamine phosphate and hexadecenal $[38,39]$ (Figure 1). Significantly, S-1-P is released from cells to act extracellularly in an auto- and paracrine fashion via interaction with G-Protein Coupled Receptors (GPCR's) [40,41]. Activation of these GPCRs increases several pro-cancer functions including growth, survival, motility, angiogenesis, lymphangiogenesis and metastasis [42]. It is thought that S-1-P can exit a cell either via the specific transporter Spns2 or one of the ATP-Binding Cassette Transporters (ABCs) [43-45]; it's more amphipathic nature (alkyl chain plus phosphate group), makes this possible. This is known as "inside-out" signaling (Figure 3). It is also found in serum at levels significantly higher than intracellularly (high vs. low nanomolar respectively) where it is associated with lipoproteins and albumen [46]. Sphingosine-1-phosphate can even enter cells via the cystic fibrosis transmembrane regulator (Figure 3) [47]. Due to the interconnected nature of sphingolipid metabolism, changes in the level of one or more family members can affect the levels of many other family members. The application of high-performance liquid chromatography-tandem mass spectrometry has revealed the cellular levels of many sphingolipids [48] suggesting, in effect, a concentration gradient from sphingomyelins (high levels in membranes) to S-1-P (low nanomolar concentrations) via ceramide and sphingosine. The level of each family member decreases by roughly an order of magnitude from the previous one [46]. Thus it can be appreciated that small changes in ceramide levels may cause significant changes in S-1-P levels [1]. This has given rise to the concept of a sphingolipid "rheostat" affecting, in particular, the crucially important cell process

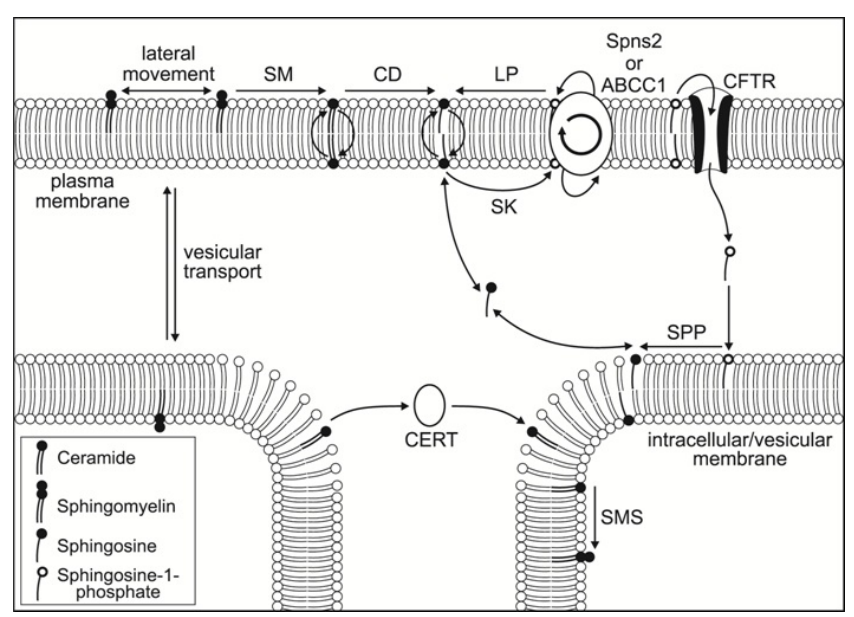

Figure 3: Movement of some of the most important sphingolipids within the cell. "Complex" sphingolipids such as sphingomyelin have limited aqueous solubility, requiring vesicular transport within a cell, and can rarely flipflop across a membrane due to the amphipathic nature. They are capable of lateral movement however. Recycling of sphingomyelin via the action of Sphingomyelinase (SM) and subsequently Ceramidase (CD) yields ceramide and then sphingosine respectively; ceramide and especially sphingosine can flip-flop across a membrane but still have limited aqueous solubility, ceramide requiring either vesicular transport or specific transfer proteins to move within the cell (CERT). Sphingosine Kinase (SK) can phosphorylate sphingosine to sphingosine-1-phosphate which can enter the cytosol but cannot cross membranes; it is thought that either an $A B C$ transporter (ABCC1) or the specific transporter Spns2 will allow it to exit the cell (allowing it to interact with its G-protein receptors) while the Cystic Fibrosis Transmembrane Regulator (CFTR) is implicated in its entry. Other abbreviations; LP, Lipid Phosphatases; SPP, Sphingophosphate Phosphatase; SMS, Sphingomyelin Synthase. Adapted from Hannun and Obeid [1]. of apoptosis; an increase in ceramide with a decrease in S-1-P favoring apoptotic pathways (a "left shift" in figure 1) whereas a decrease in ceramide with an increase in S-1-P favoring anti-apoptotic pathways (a "right shift" in figure 1) [49].

\section{Sphingolipid Function: Ceramide}

Although many sphingolipids appear to have various and important messenger functions, we will limit our principal discussion hereto those best characterized so far and potentially the most important member's ceramide and S-1-P especially as they relate to apoptosis. Apoptosis, also known as programmed cell death, is a normal cellular process whereby old, unnecessary or unhealthy cells can be safely eliminated. It is of particular importance in controlling and preventing the development of cancer cells and tumorigenesis. To briefly summarize, apoptosis can be stimulated via 2 general pathways; the extrinsic and intrinsic pathways. As their names suggest, the extrinsic results from external ligands binding to so-called "death receptors" (FasL or TNF- $\alpha$ ) while the intrinsic is triggered either by nuclear or mitochondrial dysfunction. Regardless of the route the final result is the activation of various caspases and apoptosis. It is thought that ceramide, released from sphingomyelin in lysosomes by the action of acid sphingomyelinase [1,34], can form channels in the outer mitochondrial membrane. This allows the release of pro-apoptotic proteins such as cytochrome c, procaspases, apoptosis inducing factor, heat shock proteins, Smac/Diablo and endonuclease $G$ which are crucial for apoptosis [50]. Acid sphingomyelinase release of ceramide is stimulated by TNFa, CD95 and certain chemotherapeutic agents [51]. Ceramide activates cathepsin $\mathrm{D}$ to induce apoptosis via activating BID [34]. Ceramide's other principal targets include PP1 and PP2A which are involved in regulating apoptosis and cell growth arrest [52,53]. Ceramide also targets the kinase suppressor Ras which helps regulate TNFa-mediated activation of ERK1 and 2 in intestinal epithelial cells [54,55], activation of c-Raf and the Mitogen-Activated Protein Kinase (MAPK) pathway in kidney glomerular mesangial cells [56], and many members of the PKC family [57-59]. Ceramide can bind to and activate Stress-Activated Protein Kinase (SAPK/JNK) and cause kidney glomerular epithelial cells to undergo apoptosis distinct from the previously mentioned effect in mesangial cells via MAPK [60]. Ceramide is also implicated in metabolic syndrome and the development of type 2 diabetes. Excess saturated fatty acid levels and inflammatory cytokines such as TNF- $\alpha$ cause an increase in ceramide which, via PP2A, activates PKB/Akt and lowers insulin sensitivity [61]. Finally it has been shown that both ceramide and S-1-P can cause autophagy. Autophagy is the cellular recycling of organelles and macromolecules principally for energy homeostasis; it is also implicated in certain immune responses, stress, neurodegeneration, aging and cancer [62]. Normally AKT inhibits autophagy via mTOR kinase; if growth conditions become unfavorable this inhibition is removed $[63,64]$. Tamoxifen, which can induce autophagy, is known to act via sphingolipids $[65,66]$. C2-ceramide, a synthetic Ser/Thr protein phosphatase activator, can cause autophagy via beclin-1 upregulation in MCF-1 cells similarly to tamoxifen [66]. Sphingosine-1-phosphate appears to activate autophagy by inhibiting mTOR but independently of AKT [67].

\section{Sphingosine-1-Phosphate}

Sphingosine-1-phosphate is typically found at very low concentrations within cells, but higher in plasma, and is thought to act principally via extracellular GPCR's [44]. Sphingosine-1-phosphate has been shown to be essential for immune cell migration from lymphoid 
tissue to the site of disease so this gradient and dependency on cell surface GPR's (specifically S1PR1) might be expected [68,69]. In plas$\mathrm{ma}$ it is associated primarily with high-density lipoproteins and is thought to contribute in some way to the protective effects of these lipoproteins [70]. It is also found in high levels in platelets where it is released rapidly upon platelet activation [71]. The 5 currently known S-1-P GPCR's (S1PR1-5) display differential tissue expression and link to typical heterotrimeric $\mathrm{G}$-protein pathways including $\mathrm{G}_{\mathrm{i}}, \mathrm{G}_{\mathrm{q}}$ and $\mathrm{G}_{12}$ [72-74]. The S1PR1 receptor is central in lymphocyte tracking [75]. Circulating S-1-P acting via GPCR's is also significant in regulating vascular permeability during inflammation [76]. It is also probably necessary for activation of STAT3 which is a transcription factor known to be involved in several forms of cancer and metastasis. Interestingly, STAT3 acts to upregulate S1PR1 expression producing in effect a positive feedback loop $[77,78]$. The S1PR1 receptor also activates MAPK [79] and in knockout mice deletion of S1PR1 is embryonic lethal as it is required for angiogenesis (deletion of S1PR2 or 3 is not) [80]. The receptors S1PR4 and 5 are also implicated in immune cell movement $[81,82]$. Sphingosine-1-phosphate is also thought to have intracellular targets but these are not as well characterized currently. One such intracellular target are the Histone Deacetylases (HDAC's); S-1-P increases histone acetylation via inhibition of HDACs which is tumoriogenic $[83,84]$. Recent research has implicated S-1-P in amyloid- $\beta$-peptide processing in neurons suggesting it may affect the progression of alzheimer's disease [85]. Unlike ceramide, S-1-P inhibits apoptosis and promotes cell proliferation and can therefore be tumorigenic; there has been much research recently into sphingosine kinase inhibitors [86,87]. Sphingosine kinase is affected by many factors including growth factors (PDGF, IGF and VEGF) and cytokines (TNF- $\alpha$ and IL-1) $[1,88]$. Not surprisingly there is much interest in reducing S-1-P levels and it has been additionally implicated in endothelial barrier homeostasis and viral infections [87]. Sphingolipids, especially ceramide, are also thought to be involved in many aspects of inflammation. This includes the activation of the transcription factor $\mathrm{NF}-\mathrm{XB}$ which affects many genes including those encoding cytokines and chemokines $[89,90]$. Recently it has been shown that ceramide may be involved in lung inflammation in cystic fibrosis [91]. When large amounts of ceramide are generated they can actually change the biophysical properties of a membrane [92]. The reader is recommended to the excellent review by Meer et al. [93]. Research has shown $\mathrm{S}-1-\mathrm{P}$ is also involved in mast cell function. Binding to the $\mathrm{IgE}$ receptor activates sphingosine kinase, (principally type 2 ), and therefore generation of S-1-P [94].

\section{Complex Sphingolipids}

Gangliosides although technically complex sphingolipids are such a large subject in their own right that a discussion of their many important functions is beyond the scope of this review and the reader is referred to one of the many excellent reviews such as that by Schnaar [95]. The other complex sphingolipids can be divided into 3 broad groups depending on whether glucose, galactose or phosphocholine head groups are initially added to the $\mathrm{C} 1$ position of ceramide resulting in the formation of glucosphingolipids, galactosphingolipids (collectively known as glycosphingolipids) and sphingomyelin respectively. These are produced primarily in the golgi apparatus and can exhibit great diversity. Three major enzymes are responsible for synthesis of these complex sphingolipids and include glucosylceramide synthase, ceramide galactosyltransferase and sphingomyelin synthase respectively [14]. Glucosylceramide is produced in the golgi apparatus from ceramide and UDP-glucose by glucosylceramide synthase [96].
Glucosylceramide is transported via the lipid transport protein FAPP2 [97]. Unlike galactosylceramide, glucosylceramide is essential to life in mammals; mice lacking this synthase are embryonic lethal but the condition can be rescued by addition of exogenous glucosylceramide. It is thought that these sphingolipids are essential for correct cell-cell recognition [98]. Mouse knockouts of glucosylceramide synthase confined to the skin or nervous system lead to either a breakdown of the hydrophobic barrier of the skin (excessive water loss followed by death) or death 11-24 days after birth, apparently due to a lack of proper brain development respectively [99,100]. Galactosylceramide is produced by ceramide galactosyltransferase from ceramide and UDP-galactose in the endoplasmic reticulum [101]. Although this enzyme appears to have limited tissue expression (kidneys, testes and intestines) it is found in myelinating glial cells both in the CNS and peripheral nervous system (oligodendrocytes and schwann cells respectively). In the CNS, myelin has a significant galactosylceramide content and knockout mice for ceramide galactosyltransferase display severe motor weakness among other problems such as male infertility $[102,103]$. Sphingomyelin is the commonest complex sphingolipid found in mammalian cells and is essential for survival [14,104]. There are 3 sphingomyelin synthases found primarily in the golgi apparatus but also in the cell membrane where they may be involved in maintaining sphingolipid content $[30,105]$. The synthesis of sphingomyelin from ceramide and phosphatidylcholine also produces DAG which has opposite effects to ceramide on proliferation and cell survival [106]. Vitamin $\mathrm{D}_{3}$ stimulates sphingomyelinase activity and results in an increase in ceramide levels due to sphingomyelin breakdown [107]. Apart from the generation of signaling molecules, complex sphingolipids are necessary for maintaining membrane structure and certain functional microdomains $[108,109]$. They are also binding sites for various proteins as well as certain bacterial and viral pathogens and toxins $[110,111]$. Some sphingolipids are actually covalently attached to membrane proteins [112]. Importantly it has been shown that depletion of complex sphingolipids from plasma membranes due to fumonisin-mediated disruption of sphingolipid metabolism (a fungal toxin that inhibits CerS) affects endocytosis of folate via human folate receptor $\alpha$. Folate is required for correct development of the CNS and a deficiency in animals and humans causes an increase in Neural Tube Defects, (NTD's). Fumonisins have been shown to cause this in animal models and are strongly implicated in increased incidences of NTD's in humans where fumonisin-contaminated foods have been consumed [113].

\section{Pharmacological Targeting}

Sphingolipids are involved or implicated in many vital cell processes and pathologies. The simple rheostat model suggests that a shift in the intracellular sphingolipid profile towards ceramide versus S-1-P will favor apoptosis (Figure 1) and therefore the possible removal of cancer cells. Inhibition of SphKs should decrease the generation of S-1-P and were therefore an obvious early target of research but even though decreases in S-1-P were often seen, sometimes with a corresponding increase in ceramide, the results were mixed [114-118]. The specific SphK2 inhibitor ABC294640 did inhibit several cancerous cell types in culture and decrease S-1-P levels in mice but also has demonstrated anti-estrogenic effects $[118,119]$. Neutralizing of S-1-P via monoclonal antibodies looked promising with murine models showing a decrease in lung cancer metastasis but a human version has just recently failed a phase III trial for the treatment of renal cancer (Sonepcizumab) [120,121]; http://adisinsight.springer.com/ drugs/800024045). However this drug is still being considered for the 
Citation: Nicholas JD Wright (2016) A Beginners Guide to the Metabolism, Functions and Pharmacological Potential of Sphingolipids. J Pharmacol Pharmaceut Pharmacovigil 1: 001.

treatment of wet age-related macular degeneration such as the prevalence of sphingolipid signaling. Research is also underway to develop drugs that activate S-1-P lyase as a means to decrease S-1-P [122]. Significant features of many cancers are their resistance to death receptor ligands and mitochondrial-induced apoptosis. Cancer cells typically have disrupted apoptotic pathways with an imbalance of pro-versus anti-apoptotic proteins [5]. Low levels of ceramide are observed in certain breast, colon and kidney cancers [123-126]. Elevation of ceramide levels should favor receptor clustering and therefore apoptosis [127]. Additionally, ceramide-enriched "platforms" can allow cell membrane invaginations sufficient to interact with mitochondria and trigger apoptosis in a blurring of the extrinsic and extrinsic pathways (the so-called "kiss of death") [128,129]. Ceramide has the additional problem of being severely hydrophobic so drug delivery is a factor that needs to be considered if trying to directly increase ceramide levels by supplementation [130]. In the light of often contradictory results it is now becoming fairly obvious that a more refined rheostat model needs to be developed which could take into account such confounders as subcellular location and differing alkyl chain lengths, etc. in ceramide and its derivatives (see CerS previously) [131]. It may be that a pharmacogenetic profile will need to be taken of the patient's sphingolipid-metabolizing enzymes to be fitted to a model to predict the desired, patient-specific manipulation, possibly requiring multiple pharmacological agents. Finally the rheostat model can be by-passed by targeting the actual receptors involved. In the case of S-1-P, these are the S1PR's activated by extracellular S-1-P, especially S1PR1 whose activation is involved in several cancers. This particular avenue of research is now producing second generation drugs. One of the most promising has been fingolimod which is a sphingosine analog that is phosphorylated into an S-1-P analog by SphK2 and acts as an agonist on all the S1PR's except S1PR2 [132,133] (Figure 2). Although an agonist it actually reduces the effect of S1PR1 activation by triggering receptor internalization $[132,134]$, a form of cellular adaptation. Additionally fingolimod itself can induce apoptosis via the dephosphorylation of oncogenic proteins by PP2A [135-138]. However, fingolimod was found not to be particularly useful in combatting cancer but in treating Multiple Sclerosis (MS) where its inhibition of immune cell movement into the CNS was efficacious [69]. This drug has been approved by the FDA for the treatment of MS for several years now and is reviewed in far greater depth in the 2013 Nature Reviews of Drug Discovery (volume 12, number 9) which lists many sphingomimetics, etc. already being developed to treat various pathologies. There is still much to learn about sphingolipids but the future looks promising for the development of a plethora of new drugs that can manipulate sphingolipid metabolism and treat many pathologies.

\section{Conflict of Interest}

The author has no conflicts of interest nor has published or has being considered for publication any part of this manuscript elsewhere.

\section{Acknowledgement}

Big thanks to Vanessa Wright for her help in preparing the figures.

\section{References}

1. Hannun YA, Obeid LM (2008) Principles of bioactive lipid signalling: lessons from sphingolipids. Nat Rev Mol Cell Biol 9: 139-150.

2. Nishizuka $Y(1992)$ Intracellular signaling by hydrolysis of phospholipids and activation of protein kinase C. Science 258: 607-614.

3. Vane JR (1976) Prostaglandins as mediators of inflammation. Adv Prostaglandin Thromboxane Res 2: 791-801.
4. Pewzner-Jung Y, Ben-Dor S, Futerman AH (2006) When do Lasses (longevity assurance genes) become CerS (ceramide synthases)?: Insights into the regulation of ceramide synthesis. J Biol Chem 281: 25001-25005.

5. Lahiri S, Futerman AH (2005) LASS5 is a bona fide dihydroceramide synthase that selectively utilizes palmitoyl-CoA as acyl donor. J Biol Chem 280: 33735-33738.

6. Lucki NC, Sewer MB (2012) Nuclear sphingolipid metabolism. Annu Rev Physiol 74: 131-151.

7. Posse de Chaves E, Sipione S (2010) Sphingolipids and gangliosides of the nervous system in membrane function and dysfunction. FEBS Lett 584 : 1748-1759.

8. Yu RK, Tsai YT, Ariga T, Yanagisawa M (2011) Structures, biosynthesis, and functions of gangliosides--an overview. J Oleo Sci 60: 537-544.

9. Morad SA, Cabot MC (2013) Ceramide-orchestrated signalling in cancer cells. Nat Rev Cancer 13: 51-65.

10. Thudichum JLW (1884) A Treatise on the Chemical Constitution of Brain. Bailliere, Tindall and Cox, London, Uk.

11. Carter HE, Haines WJ, et al. (1947) Biochemistry of the sphingolipides; preparation of sphingolipides from beef brain and spinal cord. J Biol Chem 169: 77-82.

12. Hakomori S (1983) Chemistry of Glycosphingolipids. In: Kanfer JN, Hakomori S (eds.). Sphingolipid Biochemistry, Springer, USA.

13. www.sphingomap.org

14. Sullards MC, Allegood JC, Kelly S, Wang E, Haynes CA, et al. (2007) Structure-specific, quantitative methods for analysis of sphingolipids by liquid chromatography-tandem mass spectrometry: "inside-out" sphingolipidomics. Methods Enzymol 432: 83-115.

15. Gault CR, Obeid LM, Hannun YA (2010) An overview of sphingolipid metabolism: from synthesis to breakdown. Adv Exp Med Biol 688: 1-23.

16. Mandon EC, Ehses I, Rother J, van Echten G, Sandhoff K (1992) Subcellular localization and membrane topology of serine palmitoyltransferase, 3-dehydrosphinganine reductase, and sphinganine $\mathrm{N}$-acyltransferase in mouse liver. J Biol Chem 267: 11144-11148.

17. Merrill AH, Wang E, Mullins RE (1988) Kinetics of long-chain (sphingoid) base biosynthesis in intact LM cells: effects of varying the extracellular concentrations of serine and fatty acid precursors of this pathway. Biochemistry 27: $340-345$.

18. Cowart LA, Hannun YA (2007) Selective substrate supply in the regulation of yeast de novo sphingolipid synthesis. J Biol Chem 282: 12330-12340.

19. Bejaoui K, Wu C, Scheffler MD, Haan G, Ashby P, et al. (2001) SPTLC1 is mutated in hereditary sensory neuropathy, type 1 . Nat Genet 27: 261-262.

20. Dawkins JL, Hulme DJ, Brahmbhatt SB, Auer-Grumbach M, Nicholson GA (2001) Mutations in SPTLC1, encoding serine palmitoyl transferase, long chain base subunit-1, cause hereditary sensory neuropathy type I. Nat Genet $27: 309-312$.

21. Gupta SD, Gable K, Han G, Borovitskaya A, Selby L, et al. (2009) Tsc10p and FVT1: topologically distinct short-chain reductases required for longchain base synthesis in yeast and mammals. J Lipid Res 50: 1630-1640.

22. Lahiri S, Lee H, Mesicek J, Fuks Z, Haimovitz-Friedman A, et al. (2007) Kinetic characterization of mammalian ceramide synthases: determination of $\mathrm{K}(\mathrm{m})$ values towards sphinganine. FEBS Lett 581: 5289-5294.

23. Xu R, Jin J, Hu W, Sun W, Bielawski J, et al. (2006) Golgi alkaline ceramidase regulates cell proliferation and survival by controlling levels of sphingosine and S1P. FASEB J 20: 1813-1825.

24. Galadari S, Wu BX, Mao C, Roddy P, El Bawab S, et al. (2006) Identification of a novel amidase motif in neutral ceramidase. Biochem J 393: 687-695. 
Citation: Nicholas JD Wright (2016) A Beginners Guide to the Metabolism, Functions and Pharmacological Potential of Sphingolipids. J Pharmacol Pharmaceut Pharmacovigil 1: 001.

25. Cadena DL, Kurten RC, Gill GN (1997) The product of the MLD gene is a member of the membrane fatty acid desaturase family: overexpression of MLD inhibits EGF receptor biosynthesis. Biochemistry 36: 6960-6967.

26. Bielawska A, Crane HM, Liotta D, Obeid LM, Hannun YA (1993) Selectivity of ceramide-mediated biology. Lack of activity of erythro-dihydroceramide. J Biol Chem 268: 26226-26232.

27. Sugiura M, Kono K, Liu H, Shimizugawa T, Minekura H, et al. (2002) Ceramide kinase, a novel lipid kinase. Molecular cloning and functional characterization. J Biol Chem 277: 23294-23300

28. Boudker O, Futerman AH (1993) Detection and characterization of ceramide-1-phosphate phosphatase activity in rat liver plasma membrane. J Biol Chem 268: 22150-22155.

29. Hanada K, Kumagai K, Tomishige N, Kawano M (2007) CERT and intracellular trafficking of ceramide. Biochim Biophys Acta 1771: 644-653.

30. Raas-Rothschild A, Pankova-Kholmyansky I, Kacher Y, Futerman AH (2004) Glycosphingolipidoses: beyond the enzymatic defect. Glycoconj J 21: 295304.

31. Tafesse FG, Ternes P, Holthuis JC (2006) The multigenic sphingomyelin synthase family. J Biol Chem 281: 29421-29425.

32. Hakomori S (2000) Traveling for the glycosphingolipid path. Glycoconj J 17 627-647.

33. Ichikawa S, Hirabayashi Y (1998) Glucosylceramide synthase and glycosphingolipid synthesis. Trends Cell Biol 8: 198-202.

34. Marchesini N, Hannun YA (2004) Acid and neutral sphingomyelinases: roles and mechanisms of regulation. Biochem Cell Bio 82: 27-44.

35. Heinrich M, Neumeyer J, Jakob M, Hallas C, Tchikov V, et al. (2004) Cathepsin D links TNF-induced acid sphingomyelinase to Bid-mediated caspase- 9 and -3 activation. Cell Death Differ 11: 550-563.

36. Hait NC, Oskeritzian CA, Paugh SW, Milstien S, Spiegel S (2006) Sphingosine kinases, sphingosine 1-phosphate, apoptosis and diseases. Biochim Biophys Acta 1758: 2016-2026

37. Johnson KR, Johnson KY, Becker KP, Bielawski J, Mao C, et al. (2003) Role of human sphingosine-1-phosphate phosphatase 1 in the regulation of intra- and extracellular sphingosine-1-phosphate levels and cell viability. J Biol Chem 278: 34541-34547.

38. Spiegel S (1999) Sphingosine 1-phosphate: a prototype of a new class of second messengers. J Leukoc Biol 65: 341-344.

39. Van Veldhoven PP, Mannaerts GP (1991) Subcellular localization and membrane topology of sphingosine-1-phosphate lyase in rat liver. J Biol Chem 266: 12502-12507.

40. Bandhuvula P, Saba JD (2007) Sphingosine-1-phosphate lyase in immunity and cancer: silencing the siren. Trends Mol Med 13: 210-217.

41. Taha TA, Argraves KM, Obeid LM (2004) Sphingosine-1-phosphate receptors: receptor specificity versus functional redundancy. Biochim Biophys Acta 1682: 48-55.

42. Hobson JP, Rosenfeldt HM, Barak LS, Olivera A, Poulton S, et al. (2001) Role of the sphingosine-1-phosphate receptor EDG-1 in PDGF-induced cell motility. Science 291: 1800-1803.

43. Pyne NJ, Pyne S (2010) Sphingosine 1-phosphate and cancer. Nat Rev Cancer 10: 489-503.

44. Mitra P, Oskeritzian CA, Payne SG, Beaven MA, Milstien S, et al. (2006) Role of ABCC1 in export of sphingosine-1-phosphate from mast cells. Proc Natl Acad Sci U S A 103: 16394-16399.

45. Takabe K, Spiegel S (2014) Export of sphingosine-1-phosphate and cancer progression. J Lipid Res 55: 1839-1846.

46. Kim RH, Takabe K, Milstien S, Spiegel S (2009) Export and functions of sphingosine-1-phosphate. Biochim Biophys Acta 1791: 692-696.
47. Okajima $F$ (2002) Plasma lipoproteins behave as carriers of extracellular sphingosine 1-phosphate: is this an atherogenic mediator or an anti-atherogenic mediator? Biochim Biophys Acta 1582: 132-137.

48. Boujaoude LC, Bradshaw-Wilder C, Mao C, Cohn J, Ogretmen B, et al (2001) Cystic fibrosis transmembrane regulator regulates uptake of sphingoid base phosphates and lysophosphatidic acid: modulation of cellular activity of sphingosine 1-phosphate. J Biol Chem 276: 35258-35264.

49. Bielawski J, Szulc ZM, Hannun YA, Bielawska A (2006) Simultaneous quantitative analysis of bioactive sphingolipids by high-performance liquid chromatography-tandem mass spectrometry. Methods 39: 82-91.

50. Cuvillier O, Pirianov G, Kleuser B, Vanek PG, Coso OA, et al. (1996) Suppression of ceramide-mediated programmed cell death by sphingosine-1-phosphate. Nature 381: 800-803.

51. Saelens X, Festjens N, Vande Walle L, van Gurp M, van Loo G, et al. (2004) Toxic proteins released from mitochondria in cell death. Oncogene 23: 28612874.

52. Heinrich M, Wickel M, Winoto-Morbach S, Schneider-Brachert W, Weber T, et al. (2000) Ceramide as an activator lipid of cathepsin D. Adv Exp Med Biol 477: 305-315.

53. Obeid LM, Linardic CM, Karolak LA, Hannun YA (1993) Programmed cell death induced by ceramide. Science 259: 1769-1771.

54. Chalfant CE, Kishikawa K, Mumby MC, Kamibayashi C, Bielawska A, et al. (1999) Long chain ceramides activate protein phosphatase-1 and protein phosphatase-2A. Activation is stereospecific and regulated by phosphatidic acid. J Biol Chem 274: 20313-20317.

55. Zhang Y, Yao B, Delikat S, Bayoumy S, Lin XH, et al. (1997) Kinase suppressor of Ras is ceramide-activated protein kinase. Cell 89: 63-72.

56. Yan F, John SK, Polk DB (2001) Kinase suppressor of Ras determines survival of intestinal epithelial cells exposed to tumor necrosis factor. Cancer Res 61: 8668-8675.

57. Huwiler A, Brunner J, Hummel R, Vervoordeldonk M, Stabel S, et al. (1996) Ceramide-binding and activation defines protein kinase c-Raf as a ceramide-activated protein kinase. Proc Natl Acad Sci U S A 93: 6959-6963.

58. Kajimoto T, Shirai Y, Sakai N, Yamamoto T, Matsuzaki H, et al. (2004) Ceramide-induced apoptosis by translocation, phosphorylation, and activation of protein kinase Cdelta in the Golgi complex. J Biol Chem 279: 12668-12676.

59. Aschrafi A, FranzenR, Shabahang S, Fabbro D, Pfeilschifter J, et al. (2003) Ceramide induces translocation of protein kinase C-alpha to the Golgi compartment of human embryonic kidney cells by interacting with the $\mathrm{C} 2$ domain. Biochim Biophys Acta 1634: 30-39.

60. Kashiwagi K, Shirai Y, Kuriyama M, Sakai N, Saito N (2002) Importance of C1B domain for lipid messenger-induced targeting of protein kinase C. J Biol Chem 277: 18037-18045.

61. Huwiler A, Xin C, Brust AK, Briner VA, Pfeilschifter J (2004) Differential binding of ceramide to MEKK1 in glomerular endothelial and mesangial cells. Biochim Biophys Acta 1636: 159-168.

62. Summers SA (2006) Ceramides in insulin resistance and lipotoxicity. Prog Lipid Res 45: 42-72.

63. Oskouian B, Saba JD (2010) Cancer treatment strategies targeting sphingolipid metabolism. Adv Exp Med Biol 688: 185-205.

64. Wullschleger S, Loewith R, Hall MN (2006) TOR signaling in growth and metabolism. Cell 124: 471-484.

65. Takeuchi H, Kondo Y, Fujiwara K, Kanzawa T, Aoki H, et al. (2005) Synergistic augmentation of rapamycin-induced autophagy in malignant glioma cells by phosphatidylinositol 3-kinase/protein kinase B inhibitors. Cancer Res 65 : 3336-3346.

66. Seglen PO, Gordon PB (1982) 3-Methyladenine: specific inhibitor of autophagic/lysosomal protein degradation in isolated rat hepatocytes. Proc Nat Acad Sci USA 79: 1889-1892. 
Citation: Nicholas JD Wright (2016) A Beginners Guide to the Metabolism, Functions and Pharmacological Potential of Sphingolipids. J Pharmacol Pharmaceut Pharmacovigil 1: 001.

67. Scarlatti F, Bauvy C, Ventruti A, Sala G, Cluzeaud F, et al. (2004) Ceramide-mediated macroautophagy involves inhibition of protein kinase $B$ and up-regulation of beclin 1. J Biol Chem 279: 18384-18391.

68. Boya P, González-Polo RA, Casares N, Perfettini JL, Dessen P, et al. (2005) Inhibition of macroautophagy triggers apoptosis. Mol Cell Biol 25: 1025-1040.

69. Spiegel S, Milstien S (2011) The outs and the ins of sphingosine-1-phosphate in immunity. Nat Rev Immunol 11: 403-415.

70. Pham TH, Okada T, Matloubian M, Lo CG, Cyster JG (2008) S1P1 receptor signaling overrides retention mediated by $\mathrm{G}$ alpha i-coupled receptors to promote T cell egress. Immunity 28: 122-123.

71. Kimura T, Sato K, Kuwabara A, Tomura H, Ishiwara M, et al. (2001) Sphingosine 1-phosphate may be a major component of plasma lipoproteins responsible for the cytoprotective actions in human umbilical vein endothelia cells. J Biol Chem 276: 31780-31785.

72. Kobayashi N, Nishi T, Hirata T, Kihara A, Sano T, et al. (2006) Sphingosine 1-phosphate is released from the cytosol of rat platelets in a carrier-mediated manner. J Lipid Res 47: 614-621.

73. Lee MJ, Van Brocklyn JR, Thangada S, Liu CH, Hand AR, et al. (1998) Sphingosine-1-phosphate as a ligand for the $G$ protein-coupled receptor EDG-1. Science 279: 1552-1555.

74. Meyer zu Heringdorf D, Jakobs KH (2007) Lysophospholipid receptors: signalling, pharmacology and regulation by lysophospholipid metabolism. Biochim Biophys Acta 1768: 923-940.

75. Windh RT, Lee MJ, Hla T, An S, Barr AJ, et al. (1999) Differential coupling of the sphingosine 1-phosphate receptors Edg-1, Edg-3, and H218/Edg-5 to the $\mathrm{G}(\mathrm{i}), \mathrm{G}(\mathrm{q})$, and $\mathrm{G}(12)$ families of heterotrimeric $\mathrm{G}$ proteins. J Biol Chem 274: $27351-27358$.

76. Schwab SR, Cyster JG (2007) Finding a way out: lymphocyte egress from lymphoid organs. Nat Immunol 8: 1295-1301.

77. Camerer E, Regard JB, Cornelissen I, Srinivasan Y, Duong DN, et al. (2009) Sphingosine-1-phosphate in the plasma compartment regulates basal and inflammation-induced vascular leak in mice. J Clin Invest 119: 1871-1879.

78. Lee H, Deng J, Kujawski M, Yang C, Liu Y, et al. (2010) STAT3-induced S1PR1 expression is crucial for persistent STAT3 activation in tumors. Nat Med 16: 1421-1428.

79. Deng J, Liu Y, Lee H, Herrmann A, Zhang W, et al. (2012) S1PR1-STAT3 signaling is crucial for myeloid cell colonization at future metastatic sites. Cancer Cell 21: 642-654

80. Okamoto H, Takuwa N, Gonda K, Okazaki H, Chang K, et al. (1998) EDG1 is a functional sphingosine-1-phosphate receptor that is linked via a $\mathrm{Gi} / \mathrm{o}$ to multiple signaling pathways, including phospholipase $\mathrm{C}$ activation, Ca2+ mobilization, Ras-mitogen-activated protein kinase activation, and adenylate cyclase inhibition. J Biol Chem 273: 27104-27110.

81. Liu Y, Wada R, Yamashita T, Mi Y, Deng CX, et al. (2000) Edg-1, the G protein-coupled receptor for sphingosine-1-phosphate, is essential for vascular maturation. J Clin Invest 106: 951-961.

82. Jenne CN, Enders A, Rivera R, Watson SR, Bankovich AJ, et al. (2009) T-bet-dependent S1P5 expression in NK cells promotes egress from lymph nodes and bone marrow. J Exp Med 206: 2469-2481.

83. Allende ML, Bektas M, Lee BG, Bonifacino E, Kang Jet al. (2010) Sphingosine-1-phosphate lyase deficiency produces a pro-inflammatory response while impairing neutrophil trafficking. J Biol Chem 286: 7348-7358.

84. Hait NC, Allegood J, Maceyka M, Strub GM, Harikumar KB, et al. (2009) Regulation of histone acetylation in the nucleus by sphingosine-1-phosphate. Science 325: 1254-1257.

85. Hait NC, Wise LE, Allegood JC, O'Brien M, Avni D, et al. (2014) Active, phosphorylated fingolimod inhibits histone deacetylases and facilitates fear extinction memory. Nat Neurosci 17: 971-980.
86. Takasugi N, Sasaki T, Suzuki K, Osawa S, Isshiki H, et al. (2011) BACE1 activity is modulated by cell-associated sphingosine-1-phosphate. J Neurosci 31: 6850-6857.

87. Spiegel S, Milstien S (2003) Sphingosine-1-phosphate: an enigmatic signalling lipid. Nat Rev Mol Cell Biol 4: 397-407.

88. Maceyka M, Milstien S, Spiegel S (2009) Sphingosine-1-phosphate: the Swiss army knife of sphingolipid signaling. J Lipid Res 50: 272-276.

89. Alemany R, van Koppen CJ, Danneberg K, Ter Braak M, Meyer Zu Heringdorf D (2007) Regulation and functional roles of sphingosine kinases. Naunyn Schmiedebergs Arch Pharmacol 374: 413-428.

90. Schutze S, Potthoff K, Machleidt T, Berkovic D, Wiegmann K, et al. (1992) TNF activates NF-kappa B by phosphatidylcholine-specific phospholipase C-induced "acidic" sphingomyelin breakdown. Cell 71: 765-776.

91. Xiao C, Ghosh S (2005) NF-kappaB, an evolutionarily conserved mediator of immune and inflammatory responses. Adv Exp Med Biol 560: 41-45.

92. Megha, Sawatzki P, Kolter T, Bittman R, London E (2007) Effect of ceramide $\mathrm{N}$-acyl chain and polar headgroup structure on the properties of ordered lipid domains (lipid rafts). Biochim Biophys Acta 1768: 2205-2212.

93. van Meer G, Voelker DR, Feigenson GW (2008) Membrane lipids: where they are and how they behave. Nat Rev Mol Cell Biol 9: 112-124.

94. Olivera A, Mizugishi K, Tikhonova A, Ciaccia L, Odom S, et al. (2007) The sphingosine kinase-sphingosine-1-phosphate axis is a determinant of mast cell function and anaphylaxis. Immunity 26: 287-297.

95. Schnaar RL (2016) Gangliosides of the Vertebrate Nervous System. J Mol Biol 428: 3325-3336.

96. Ichikawa S, Sakiyama H, Suzuki G,HidariKI, Hirabayashi Y (1996) Expression cloning of a cDNA for human ceramide glucosyltransferase that catalyzes the first glycosylation step of glycosphingolipid synthesis. Proc Natl Acad Sci USA 93: 4638-4643.

97. D’Angelo G, Polishchuk E, Di Tullio G, Santoro M, Di Campli A, et al. (2007) Glycosphingolipid synthesis requires FAPP2 transfer of glucosylceramide. Nature 449: 62-67.

98. Yamashita T, Wada R, Sasaki T, Deng C, Bierfreund U, et al. (1999) A vital role for glycosphingolipid synthesis during development and differentiation. Proc Natl Acad Sci U S A 96: 9142-9147.

99. Jennemann R, Sandhoff R, Langbein L, Kaden S, Rothermel U, et al. (2007) Integrity and barrier function of the epidermis critically depend on glucosylceramide synthesis. J Biol Chem 282: 3083-3094.

100. Jennemann R, Sandhoff R, Wang S, Kiss E, Gretz N, et al. (2005) Cell-specific deletion of glucosylceramide synthase in brain leads to severe neural defects after birth. Proc Natl Acad Sci USA 102: 12459-12464.

101.Stahl N, Jurevics H, Morell P, Suzuki K, Popko B (1994) Isolation, characterization, and expression of CDNA clones that encode rat UDP-galactose: ceramide galactosyltransferase. J Neurosci Res 38: 234-242.

102. Coetzee T, Li X, Fujita N, Marcus J, Suzuki K, et al. (1996) Molecular cloning, chromosomal mapping, and characterization of the mouse UDP-galactose:ceramide galactosyltransferase gene. Genomics 35: 215-222.

103. Fujimoto H, Tadano-Aritomi K, Tokumasu A, Ito K, Hikita T, et al. (2000) Requirement of seminolipid in spermatogenesis revealed by UDP-galactose: Ceramide galactosyltransferase-deficient mice. J Biol Chem 275: 2262322626.

104. Tafesse FG, Huitema K, Hermansson M, van der Poel S, van den Dikkenberg J, et al. (2007) Both sphingomyelin synthases SMS1 and SMS2 are required for sphingomyelin homeostasis and growth in human HeLa cells. J Biol Chem 282: 17537-17547.

105. Huitema K, van den Dikkenberg J, Brouwers JF, Holthuis JC (2004) Identification of a family of animal sphingomyelin synthases. EMBO J 23: 33-44. 
Citation: Nicholas JD Wright (2016) A Beginners Guide to the Metabolism, Functions and Pharmacological Potential of Sphingolipids. J Pharmacol Pharmaceut Pharmacovigil 1: 001.

106. Villani M, Subathra M, Im YB, Choi Y, Signorelli P, et al. (2008) Sphingomyelin synthases regulate production of diacylglycerol at the Golgi. Biochem $J$ 414: $31-41$

107. Okazaki T, Bell RM, Hannun YA (1989) Sphingomyelin turnover induced by vitamin D3 in HL-60 cells. Role in cell differentiation. J Biol Chem 264 19076-19080.

108. Iwabuchi K, Handa K, Hakomori S (1998) Separation of "glycosphingolipid signaling domain" from caveolin-containing membrane fraction in mouse melanoma B16 cells and its role in cell adhesion coupled with signaling. $J$ Biol Chem 273: 33766-33773.

109. Riboni L, Viani P, Bassi R, Prinetti A, Tettamanti G (1997) The role of sphingolipids in the process of signal transduction. Prog Lipid Res 36: 153-195.

110.Karlsson KA (1986) Animal glycolipids as attachment sites for microbes. Chem Phys Lipids 42: 153-172.

111.Fantini J, Hammache D, Delezay O, Yahi N, Andre-Barres C, et al. (1997) Synthetic soluble analogs of galactosylceramide (GalCer) bind to the $\mathrm{V} 3 \mathrm{do}$ do main of HIV-1 gp120 and inhibit HIV-1-induced fusion and entry. J Biol Chem 272: $7245-7252$

112.Conzelmann A, Puoti A, Lester RL, Desponds C (1992) Two different types of lipid moieties are present in glycophosphoinositol-anchored membrane proteins of Saccharomyces cerevisiae. EMBO J 11: 457-466.

113. Missmer SA, Suarez L, Felkner M, Wang E, Merrill AH Jr, et al. (2006) Exposure to fumonisins and the occurrence of neural tube defects along the Texas-Mexico border. Environ Health Perspect 114: 237-241.

114.Abuhusain HJ, Matin A, Qiao Q, Shen H, Kain N, et al. (2013) A metabolic shift favoring sphingosine 1-phosphate at the expense of ceramide controls glioblastoma angiogenesis. J Biol Chem 288: 37355-37364.

115. Rex K, Jeffries S, Brown ML, Carlson T, Coxon A, et al. (2013) Sphingosine kinase activity is not required for tumor cell viability. PLoS One 8: 68328.

116.Schnute ME, McReynolds MD, Kasten T, Yates M, Jerome G, et al. (2012) Modulation of cellular S1P levels with a novel, potent and specific inhibitor of sphingosine kinase-1. Biochem J 444: 79-88.

117. Kharel Y, Mathews TP, Gellett AM, Tomsig JL, Kennedy PC, et al. (2011) Sphingosine kinase type 1 inhibition reveals rapid turnover of circulating sphingosine 1-phosphate. Biochem J 440: 345-353.

118. French KJ, Zhuang Y, Maines LW, Gao P, Wang W, et al. (2010) Pharmacology and antitumor activity of $A B C 294640$, a selective inhibitor of sphingosine kinase-2. J Pharmacol Exp Ther 333: 129-139.

119.Antoon JW, White MD, Meacham WD, Slaughter EM, Muir SE, et al (2010) Antiestrogenic effects of the novel sphingosine kinase-2 inhibitor ABC294640. Endocrinology 151: 5124-5135.

120.Schwalm S, Pfeilschifter J, Huwiler A (2014) Targeting the sphingosine kinase/sphingosine 1-phosphate pathway to treat chronic inflammatory kidney diseases. Basic Clin Pharmacol Toxicol 114: 44-49.

121.http://adisinsight.springer.com/drugs/800024045

122.Schwab SR, Pereira JP, Matloubian M, Xu Y, Huang Y, et al. (2005) Lymphocyte sequestration through S1P lyase inhibition and disruption of S1P gradients. Science 309: 1735-1739.

123.Zhang Y, Yoshida T, Zhang B (2009) TRAIL induces endocytosis of its death receptors in MDA-MB-231 breast cancer cells. Cancer Biol Ther 8: 917-922.
124. White-Gilbertson S, Mullen T, Senkal C, Lu P, Ogretmen B, et al. (2009) Ceramide synthase 6 modulates TRAIL sensitivity and nuclear translocation of active caspase 3 in colon cancer cells. Oncogene 28: 1132-1141.

125. Voelkel-Johnson C, Hannun YA, El-Zawahry A (2005) Resistance to TRAIL is associated with defects in ceramide signaling that can be overcome by exogenous C6-ceramide without requiring down-regulation of cellular FLICE inhibitory protein. Mol Cancer Ther 4: 1320-1327.

126. Asakuma J, Sumitomo M, Asano T, Hayakawa M (2003) Selective Akt inactivation and tumor necrosis actor-related apoptosis-inducing ligand sensitization of renal cancer cells by low concentrations of paclitaxel. Cancer Res 63: $1365-1370$

127. Stancevic B, Kolesnick R (2010) Ceramide-rich platforms in transmembrane signaling. FEBS Lett 584: 1728-1740.

128. Babiychuk EB, Atanassoff AP, Monastyrskaya K, Brandenberger C, Studer $\mathrm{D}$, et al. (2011) The targeting of plasmalemmal ceramide to mitochondria during apoptosis. PLoS One 6: 23706 .

129. Babiychuk EB, Monastyrskaya K, Draeger A (2008) Fluorescent annexin A1 reveals dynamics of ceramide platforms in living cells. Traffic 9: 1757-1775.

130. Ma YY, Mou XZ, Ding YH, Zou H, et al. (2016) Delivery systems of ceramide in targeted cancer therapy: ceramide alone or in combination with other anti-tumor agents. Expert Opin Drug Deliv 13: 1397-1406.

131. Senkal CE, Ponnusamy S, Bielawski J, Hannun YA, Ogretmen B (2010) Antiapoptotic roles of ceramide-synthase-6-generated C16-ceramide via selective regulation of the ATF6/CHOP arm of ER-stress-response pathways. FASEB J 24: 296-308.

132. Mandala S, Hajdu R, Bergstrom J, Quackenbush E, Xie J, et al. (2002) Alteration of lymphocyte trafficking by sphingosine-1-phosphate receptor agonists. Science 296: 346-349.

133. Brinkmann V, Davis MD, Heise CE, Albert R, Cottens S, et al. (2002) The immune modulator FTY720 targets sphingosine 1-phosphate receptors. J Biol Chem 277: 21453-21457.

134. Brinkmann V, Billich A, Baumruker T, Heining P, Schmouder R, et al. (2010) Fingolimod (FTY720): discovery and development of an oral drug to treat multiple sclerosis. Nat Rev Drug Discov 9: 883-897.

135. Neviani P, Santhanam R, Oaks JJ, Eiring AM, Notari M, et al. (2007) FTY720, a new alternative for treating blast crisis chronic myelogenous leukemia and Philadelphia chromosome-positive acute lymphocytic leukemia. J Clin Invest 117: $2408-2421$

136. Matsuoka Y, Nagahara Y, Ikekita M, Shinomiya T (2003) A novel immunosuppressive agent FTY720 induced Akt dephosphorylation in leukemia cells. Br J Pharmacol 138: 1303-1312.

137. Liu Q, Zhao X, Frissora F, Ma Y, Santhanam R, et al. (2008) FTY720 demonstrates promising preclinical activity for chronic lymphocytic leukemia and lymphoblastic leukemia/lymphoma. Blood 111: 275-284.

138. Roberts KG, Smith AM, McDougall F, Carpenter H, Horan M, et al. (2010) Essential requirement for PP2A inhibition by the oncogenic receptor C-KIT suggests PP2A reactivation as a strategy to treat C-KIT+ cancers. Cancer Res 70: 5438-5447. 